\title{
An Analysis of Teachers' Workshop Based on Foreign Language Teachers' Career Development
}

\author{
Cui Jingjing \\ Jinlin Business and Technology College \\ P.R. China, 130062 \\ 107851252@qq.com
}

\begin{abstract}
Based on the definition of teacher workshop and the guidance of the theory of career development of foreign language teachers, this paper explores the possibility of workshop-style teacher training, including the characteristics of workshop-style training; the combination of workshop-based training and new curriculum reform and promote the teachers team cooperation, self-participation, natural truth, sexual and flexible diversity. It is an effective ways to promote autonomous learning and group development of Foreign Language Teachers. At the same time, it explores how to improve the training content and form of teachers' workshops, and explains the necessity of implementing such training.
\end{abstract}

Keywords-teacher workshop, teacher professional development, teacher training

\section{INTRODUCTION}

With the advent of the "Internet + " era, traditional teacher training models and systems are being challenged in a revolutionary way. It has been possible to realize "Anybody, anytime, anyplace to learn any knowledge". We should promote the development of foreign language teachers and promote foreign language teaching reform and education information as the goal; constantly innovate the teacher training model, reform training management mechanism, and strive to build long-term training and short-term training, online training and offline training combined with threedimensional training. Not only can teachers continue to improve their teaching and learning ability, but also develop a network learning habits, establish a sharing and exchange awareness of cooperative learning, dynamic generation of training results to obtain a comprehensive upgrade. The workshop is a combination of physical and virtual learning platform. Entity learning platform with independent training, peer support, the host to guide and guide the integration of experts and focus on class, discussion, action research and performance. Workshops, also known as project learning workshops, initially mainly refers to a topic-based research approach to learn, and then, has evolved into a practice teaching model. "Workshop" originated in Europe (ie, the Weimar Republic period) to develop engineering design and architectural design for the purpose of Bauhaus (Staatliche Bauhaus, 1919-1937). As the pioneer of modern design, the creator of Bauhaus, one of the founders of modern architecture design, Grapius advocated the idea of "technology and art". The learning process is like "factory apprenticeship" and students' Identity is "apprenticeship". In the teaching process, teachers in the art form course called the "form tutor" to teach their theoretical courses and lead their professional development; and as a technology, handicraft production courses teachers, so we called "studio master", who were responsible for assisting to guide their practice teaching.

Due to a specific site of the practice needs, the practice of students' space, the workshop, has gradually become the core of practice, in order to form the practice mode which is also known as the "workshop teaching." Teachers workshop, this new training model, effectively strengthen the timeliness of training, sharing of experience, innovative teaching model, academic exchange and interaction, which greatly promoted the development of the teaching profession.

\section{THE MAIN FEATURES OF WORKSHOP}

Generally speaking, the term "workshop" refers to the workplace of small-scale handicraftsmen as opposed to the "factory" concept of large-scale standardized production. In the field of social sciences, it early appeared in the field of education and psychology research. In the 1960s, Lawrence Harplin of the United States introduced the concept of "workshop" into the urban plan as a way to think which succeed in exploring and communicating with people of different positions and ethnic groups. Even when it comes to urban planning or discussion of community environmental issues, it becomes a means of encouraging participation, innovation, and finding solutions. In general, a "participatory workshop" is a multi-person participation in the field and process, and allows participants make a dialogue and mutual communication, common thinking, investigation and analysis in the process, and proposed programs or planning to discuss how to make this program to promote, or even practical action, such a "gathering" and "a series of processes". That is called a participatory workshop. Richards (2005) points out that teacher workshop are considered to be one of the most popular and effective ways to promote teacher professional development, for five reasons:

1. Workshops usually explore the content, strengths and weaknesses and give professional activity to arouse teachers' interest.

2 Through short-term workshops and peer-to-peer communication activities, foreign language teachers will not only acquire expertise and skills, but will also learn practical 
ways to use their own classrooms and experience in academic research.

3 Teachers can check and reflect on their teaching beliefs and behavior.

4 The subject can be both an overall increase in the level of faculty and the professional development of teachers.

5 Workshops are arranged for the teacher' leisure time that is suitable for teachers' feature. (Dong Jinwei, 2007) [1] [2]

\section{THE CHARACTERISTICS OF TEACHER TRAINING WORKSHOPS}

Teacher workshop here refers to a hybrid teacher training model. With the support of network information technology and the help of network training platform, we should play the leading role of professional experts and teachers to lead the regional backbone teachers to carry out the normalization of full training. It is an essentially a heterogeneous learning community composed of subject experts, trainers and key teachers. Namely, it draws on the implication of the traditional hand workshop, which emphasized the silence of teachers, teaching wisdom, concise and share. Teacher workshop will focus on short-term training, network training and in-service practice which helped to achieve expert guidance, peer support and self-reflection. Through the workshop, we can carry out related topics online training and problem-solving networkbased school-based training, but also for network space teaching and other activities. The main body of the teacher workshop is a group of teachers who are trained and composed of trainees and trainees.[3] For the workshop trainers, the Ministry of Education in the relevant documents referred to as the "host", who composed by the university experts, excellent teaching and research staff (trainers) and the backbone of teachers-- "three lines" core team. Its features include the following five aspects:

\section{A. Participation.}

At present, there are many problems of teachers participate in the teacher training, such as passive participation, low degree of participation and low depth of participation. In the training process, trainers also encourage teachers to interact, but in traditional teaching mode, participating teachers are not concerned the problems. It is not easy to form a resonance and participation enthusiasm will not be high, let alone the depth of thinking. Training workshop model, emphasized the problems raised by the participating teachers, is the solution process by the teachers to complete their own training automatically. It solves a fundamental problem of training teachers, that $t$ is to say, the ignorance of the training content, so that teachers can participate in the all-round and in-depth process of teacher training. It becomes a internal requirements of workshop-style training that the combination of training and self-learning.

\section{B. Autonomy.}

Traditional training denies the autonomy of teachers participating in the study from the beginning, which advocated the participation of teachers in their own learning and active learning. In fact, the trainer, it is the "Lord "from the theme, content, methods and other aspects of the teacher training and the host becomes the "owner of the truth". Yet, the solution is different and the actual situation is in different poses and different expressions. No one can have to solve all the ultimate method. On the contrary, sometimes, it leads to the teacher's reverse psychology because the instructor and teacher training in the situation is particularly obvious differences, in which case, the training of teachers in learning autonomy and enthusiasm is out of the question. Workshop-style training emphasizes the problem selection and resolution by the participating teachers to complete autonomy. Host teachers play a guiding role in training.

\section{Self-reflection Promotion}

Effective learning is a complete process composed of concrete experience, reflective observation, abstract generalization and action application. In experiential learning, through the reflection and observation of the experiential experience, it can form a meaningful theory. However, the basis for the reflection formation is the practice, which only based on the practice, the immediate and internal reflection. It is effective, deep, multi-dimensional personal experience which is only at the ideological level. The workshop-style training provides the participants with an effective environment for reflection and opportunities.

\section{Strengthen communications and sharing}

Communication and sharing are important prerequisites for workshop-style training and an important function of workshop-style training. Within the group, the participants will share the information to the companion and everyone are in an equal position under the joint discussion to exchange views and cohesion consensus. In the course of the exchange of results between groups, group opinions and group contrasts influence teachers' educational ideas and teaching ideas in a deeper level. Options involve the results of evaluation is the criteria to evaluate the results of the superior and inferior. We believe that the promotion of teachers depends on professional growth point of view, rather than the results of their own selection and screening we should establish evaluation and development of the concept of development. Only in this way, it is more meaningful for the teacher training. Teachers through the micro-class way of the results show and exchange and each study group selected a teacher representative group to participate in the exchange of results show, ultimately, the results are original, with a strong pertinence and maneuverability, not only shows the problem-solving strategic methods, but also impressed in teaching skills and teaching methods.

\section{TEACHER WORKSHOP IS ONE OF THE EFFECTIVE WAYS OF TEACHERS' CAREER DEVELOPMENT}

Teachers' workshop, as a group approach, has a significant effect on the career development of the college English teachers. First, the training content is highly targeted and spurs teachers to resonate and stimulate their interest. Second, the interactive classroom teaching creates a relaxed atmosphere. As a colleague of the participants can be no pressure to discuss problem and learn from each other. Through the exchange, 
everyone's cooperative learning awareness has been strengthened and cooperation, enthusiasm, cooperation ability has improved significantly. Third, because it is concentrated in the holidays, the duration is not long, which is conducive to the busy work of teachers.[9]

Pedagogy training has given teachers, especially young teachers, much to gain. They have learned from their experienced colleagues a lot of practical and effective teaching experience to help them increase personal growth.

In the future teaching, we should strengthen the training of evaluation ability. Teachers' learning behavior, 'evaluation of their teaching behavior and students' is actually a reflection of behavior, "that is, teachers reflect on their own criticism of teaching behavior in order to improve the teaching of the ability to comprehend and teaching quality" (Zhang Weiyou, 2004).[10] We should make constant reflection and sum up the experience of success and failure in order to promote their career development. Based on the above analysis and feedback from participants, the following recommendations are made as follows:

1) To increase the theory of foreign language teaching training and improve the staff of teaching and research capacity especially, the teaching strategies, skills and methods, and systematic theoretical knowledge

2) To strengthen the guidance of teaching and research methods. Teachers have a wealth of teaching experience and a real classroom experiment environment. We need the effective research methods training.

3) In addition to exchanges with foreign teachers, the exchanges between Chinese teachers can be more in-depth and extensive. Due to the usual lack of mutual communication, we are difficult to reach a consensus, which is not conducive to the formation of force.

4) Teachers workshops are held every summer to provide a platform for exchange. Trainees cannot be limited to the school. We can be expanded to the brothers' institutions. In this way, we will have a wider range of communication and sharing more resources.

5) The focus of each training course and content should be different. Before the training, teachers should be provided with necessary lectures and relevant reading materials in order to be fully prepared.

6) There should be some examples of curriculum design to increase the perceptual knowledge of teachers in order to better understand the design theory and the actual operating procedures.

7) The teachers must have teaching and research experience and training staff have the similar teaching background, such as foreign counterparts, Chinese experts, and even the academic leaders of the university. It will benefit from the training for the participants.
Teachers participate in the training through teacher workshops, which promote the exchange of experience, academic exchanges and teachers 'emotional exchange. Teachers' career development is the theoretical guidance, and teachers are constantly strengthened to construct new teaching models and teaching methods. Teachers continue to enhance their career development.

\section{CONCLUSION}

Foreign language teachers need to constantly selfmonitoring, through the writing of teaching diary to reflect on their own teaching; need to cooperate with colleagues to form mutual assistance or cooperative teaching and learn from each other in order to better promote their professional development. More importantly, teachers need to constantly update the teaching philosophy, action research in order to make their own theoretical knowledge of practice and practical experience theory. The teaching management departments of the colleges and universities should try their best to create favorable development environment and conditions for the teachers so as to enable the teachers to carry out the cooperation activities to promote their professional development smoothly, which is not only for the long-term development of teachers, but is also useful for professional growth.

\section{REFERENCES}

[1] Richards, J. \& T. Farrell. Professional Development for Language Teachers: Strategies for Teacher Learning [M]. London: Cambridge University Press, 2005.

[2] Dong Jinwei, The Intentional Strategy of the Professional Development of Foreign Language Teachers---Introduction to the Teacher Professional Development: Teacher Learning Strategies [J], Foreign Language Teaching and Research, 2007 (2). .

[3] Liu Yu, Wang Laifu. Based on the Workshop of Higher Education Practice Teaching System [J]. Journal of Northeast University of Finance and Economics, 2009, (1): 93-96.

[4] Xiao Hong. "Translation Workshop" in the Use of Translation Teaching [J]. Journal of Sichuan International Studies University, 2005, (1): 139142.

[5] Jia Xiujuan.Paper Instruction Workshop: An Example of Centralized Practical Application of Project Management [J] .Ningbo Radio \& TV University, 2006, (12): 103-106

[6] Huang Chaoli. On the "Student-centered Eeducation" in the "teacher workshop" [J]. Education and Occupation, 2008, (3): 128-129.Journal of Zhejiang Institute of Education, 2011 (1): 8-12,68.

[7] YANG Guang-wei.Application of Workshop-based Learning Modes Based on Teaching Theme in the Training of Discipline Key Teachers [J]

[8] Yu Xin. Teacher Training Division Professional Practice [M]. Beijing: Educational Science Press, 2012.

[9] Ruan Xiaoqin, The Necessity and Way of Career Development of College English Teachers [J], Language and Literature Research, 2007 (6).

[10] Wang Yongmei, Through Peer co-teaching System to Promote English Teachers' Career Development [J], Foreign LanguageTeaching, 2004 (2). 